NBER WORKING PAPER SERIES

\title{
DOES SCIENTIST IMMIGRATION HARM US SCIENCE? AN EXAMINATION OF SPILLOVERS
}

\author{
Ajay Agrawal \\ John McHale \\ Alex Oettl \\ Working Paper 24519 \\ http://www.nber.org/papers/w24519 \\ NATIONAL BUREAU OF ECONOMIC RESEARCH \\ 1050 Massachusetts Avenue \\ Cambridge, MA 02138 \\ April 2018
}

We thank Bill Kerr, Joshua Gans, Avi Goldfarb, Will Strange, Scott Stern, William Lincoln, and Mercedes Delgado as well as seminar participants at Universidad Carlos III de Madrid, Harvard, and National University of Ireland, Galway for helpful comments. This research was funded by the Centre for Innovation and Entrepreneurship at the Rotman School of Management, University of Toronto, the Martin Prosperity Institute, the Social Sciences and Humanities Research Council of Canada, Science Foundation Ireland, and the Kauffman Junior Faculty Fellowship. All errors are our own. The views expressed herein are those of the authors and do not necessarily reflect the views of the National Bureau of Economic Research.

NBER working papers are circulated for discussion and comment purposes. They have not been peer-reviewed or been subject to the review by the NBER Board of Directors that accompanies official NBER publications.

(C) 2018 by Ajay Agrawal, John McHale, and Alex Oettl. All rights reserved. Short sections of text, not to exceed two paragraphs, may be quoted without explicit permission provided that full credit, including $\left({ }^{\circ}\right.$ notice, is given to the source. 
Does Scientist Immigration Harm US Science? An Examination of Spillovers

Ajay Agrawal, John McHale, and Alex Oettl

NBER Working Paper No. 24519

April 2018

JEL No. F22,J61,O33,O34

\section{ABSTRACT}

The recruitment of foreign scientists enhances US science through an expanded workforce but could also cause harm by displacing better connected domestic scientists, thereby reducing localized knowledge spillovers. We develop a model in which a sufficient condition for the absence of overall harm is that immigrant scientists generate at least the same level of localized spillovers as the domestic scientists they displace. To test this condition, we conduct an experiment in which each immigrant hypothetically displaces an appropriately matched domestic scientist. Overall, we do not find evidence that immigrant scientists harm US science by crowding out better-connected domestic scientists.

Ajay Agrawal

Rotman School of Management

University of Toronto

105 St. George Street

Toronto, ON M5S 3E6

CANADA

and NBER

ajay.agrawal@rotman.utoronto.ca

John McHale

108 Cairnes Building

School of Business and Economics

National University of Ireland, Galway

Ireland

john.mchale@nuigalway.ie
Alex Oettl

Scheller College of Business

Georgia Institute of Technology

800 West Peachtree Street, NW

Atlanta, GA 30308

Alexander.Oettl@scheller.gatech.edu 


\section{Introduction}

Innovation relies on access to knowledge. Thus, knowledge flow patterns influence innovation and hence productivity and economic growth. As a result, factors that influence knowledge flow patterns are important to understand. One such factor is immigration. In particular, immigrants may have different types of peer networks that influence how their knowledge travels across time and space. An extensive empirical literature documents that knowledge flows are geographically localized (Jaffe et al., 1993; Thompson and Fox-Kean, 2005) and that this is likely because knowledge flow patterns are influenced by intricate networks of peers who are often co-located (Agrawal et al., 2006; Waldinger, 2010). Thus, it's plausible that if immigrant scientists displace domestic scientists, then they could cause overall harm to US science by generating fewer localized spillovers because immigrants' relationships and thus knowledge flows are more internationally-oriented. This could occur even if immigrants are equally or more productive than the domestic scientists they displace. We examine the possibility of differential knowledge flows here.

In recent decades, US science has become increasingly internationalized, with rapid growth in the number of foreign-born scientists and engineers (Stephan, 2012). Between 2003 and 2013, the number of immigrant scientists increased from 0.7 million to 1.1 million (Lan et al., 2015). In the physical sciences, the number of immigrant scientists increased by 17,000 while the number of US-born scientists actually decreased by 13,000 (Table 1). With a downward-sloping demand curve for scientists and an upward sloping supply curve for US-born scientists, standard market analysis predicts that there will be displacement of US-born scientists (Borjas, 2007; Borjas and Doran, 2012).

A central theme of the economics of immigration literature has been the measurement of wage and employment displacement effects (Borjas, 2005; Kerr and Kerr, 2011; Peri, 2012; National Academies of Sciences, Engineering, and Medicine, 2016). A large body of work has 
also explored the aggregate productivity effects of immigration. In the "canonical model" (see, e.g., Borjas, 2014), the existence of aggregate gains from immigration depend on the displacement of native workers. The relatively small aggregate gain implied by this model has led researchers to look for evidence of externalities, especially in the form of knowledge spillovers (Hunt and Gauthier-Loiselle, 2010; Kerr and Lincoln, 2010; Peri, 2012; Peri et al., 2013). This has in turn led to an emphasis on peer networks that support knowledge exchange, work that connects to the large body of evidence that documents the importance of local knowledge spillovers (Freeman et al., 2015; Agrawal et al., 2015). But if local networks are critical to knowledge exchange within US science, an inflow of immigrants that displaces native workers could disrupt local knowledge networks if the immigrants are less connected to US science than the domestic scientists they displace. This raises an intriguing additional possibility of harm: US science suffers because immigrants are less well-connected to US science than the native born they displace. Essentially, scientist immigration could weaken the domestic knowledge networks that are critical to US scientific advancement.

We begin by developing a simple model of the market for scientists. A sufficient condition for the absence of immigration-induced harm to domestic science (as opposed to domestic scientists) is that immigrant scientists generate as least the same level of localized spillovers to the US scientific community as the domestic scientists they displace. In other words, there is no differential in the localized spillovers generated by immigrant versus domestic scientists. Next, we test this condition by conducting a hypothetical experiment in which each immigrant scientist is assumed to fully displace an appropriately matched US scientist. We then compare the level of citations by the US scientific community to publications by the now-US-residing immigrant scientist versus the matched (hypothetically displaced) US domestic scientist.

In the model, the combination of displacement and differential spillovers could harm US science. However, empirically, when we compare the relative citation patterns of domestic 
and immigrant scientists, we find that although the US scientific community is much less likely to cite the matched immigrant while they are in their original home country - the differential in spillovers is significant pre-immigration - their propensity to do so increases dramatically after the scientist immigrates to the US. ${ }^{1}$ In fact, the US scientific community is equally likely to cite an immigrant and a domestic scientist after the immigrant has moved to the US. In the context of our model, this absence of differential spillovers is a sufficient condition for the absence of harm. It is important to note that these are aggregate results. We do observe lower spillovers to the US scientific community from immigrants who move to universities with more co-nationals and from those who arrive from non-English speaking countries.

We further extend our analysis to focus on scientists in the right tail of the productivity distribution: "star scientists." A growing literature within the economics of science reports evidence that stars generate a disproportionate level of knowledge externalities (Azoulay et al., 2010; Waldinger, 2010; Oettl, 2012). With this subsample of elite scientists, the immigrant-generated spillover deficit disappears even more rapidly. In fact, soon after arriving, star immigrants generate more localized spillovers than their domestic peers on average.

We structure the remainder of the paper as follows. In the next section we develop a simple model of the market for scientific labor that provides a useful framework for examining the welfare implications of scientist immigration. The model allows for domestic scientist displacement and differential spillovers from domestic versus immigrant scientists. We describe our empirical strategy in Section 4 and our data and matching methodology in Section 5. We present our results in Section 6. We conclude in Section 7 with a discussion of the limitations of our findings.

\footnotetext{
${ }^{1}$ We define an immigrant scientist as one who publishes at least their first paper in a country other than the US and then at some later point begins publishing in the US. We define a domestic scientist as one who publishes their first paper in the US and then continues to publish in the US. Thus, a domestic scientist may be foreign-born. These definitions are appropriate for our purpose as we are concerned with scientists' social networks rather than their country of origin.
} 


\section{A Model of the Market for Scientists with Displace- ment and Differential Spillovers}

We develop a simple model of the market for scientists in a given country and examine factors influencing the social welfare implications of immigration. The model allows for the displacement - or "crowding out" - of domestic scientists as a result of the immigration of scientists. We adopt the ex ante social welfare perspective of the receiving country and thus ignore the welfare gains to immigrant scientists. Social welfare is thus measured by aggregate social surplus accruing to non-immigrant domestic residents; we do not focus on the distribution of that surplus. The model also allows for possible differential spillovers from domestic and immigrant scientists. We show it is possible for domestic social welfare to be harmed by immigration as a result of displacement if the difference between domestic and immigrant spillovers is large enough, even if immigration expands the overall size of the active scientific workforce. However, we show that a sufficient condition for immigration to improve domestic social welfare is that there is no difference in the size of per-scientist spillovers between domestic and immigrant scientists.

\subsection{Basic market setup}

We begin with specifications for labor supply and labor demand in the market for scientific labor. For simplicity, we assume that the units of labor are homogenous and each unit is a working scientist, although we later allow for differential spillovers between domestic and immigrant labor units. ${ }^{2}$ The supply of domestic scientists, $L_{\text {domestic }}^{s}$, is a positive linear function of the wage, $w$ :

\footnotetext{
${ }^{2}$ The model is easily extended to allow for broader heterogeneity by defining labor units in efficiency (i.e., productivity-adjusted) units. Spillovers then also would be measured per efficiency unit, so that more productive scientists are assumed to generate more spillovers.
} 


$$
L_{\text {domestic }}^{s}=\phi_{0}+\phi_{1} w \text {. }
$$

Immigrant labor units, $I$, are supplied perfectly inelastically ${ }^{3}$ (possibly due to visa-related limitations), so the total supply of labor is: ${ }^{4}$

$$
L_{\text {total }}^{s}=\phi_{0}+\phi_{1} w+I \text {. }
$$

Total labor demand, $L^{d}$, is a negative function of the wage:

$$
L^{d}=\theta_{0}-\theta_{1} w
$$

The inverse of the labor demand function is also the marginal private value function. However, we also assume that there are positive spillovers associated with each unit of scientific labor employed. The per-scientist spillover (or externality) is equal to $z(\geq 0)$, which is initially common across domestic and immigrant scientists. The marginal social value relationship is then given by:

$$
M S V=\frac{1}{\theta_{1}}\left(\theta_{0}-L\right)+z
$$

\subsection{Baseline social surplus in the absence of immigration}

As a preliminary step to establishing the effects of immigration on the market for scientific labor, we first examine the market equilibrium and social welfare in a no-immigration baseline. We graph the market equilibrium in Figure 1. The equilibrium wage and employment

\footnotetext{
${ }^{3}$ The assumption here is that the number of immigrants admitted is determined by a government policy choice (e.g. a cap on visas that are issued) and thus the number admitted is not responsive to the wage. However, all the qualitative results of the model are the same if we assume that the supply curve of immigrants is upward sloping. In particular, it remains true that a sufficient condition for the absence of harm is that there is that there is no difference in the domestic spillovers from domestic and immigrant scientists.

${ }^{4}$ In an efficiency-unit version of the model, the level of immigration is also measured in efficiency units.
} 
levels are:

$$
\begin{gathered}
w^{*}=\frac{\theta_{0}-\phi_{0}}{\phi_{1}+\theta_{1}} . \\
L^{*}=\frac{\phi_{0} \theta_{1}+\phi_{1} \theta_{0}}{\phi_{1}+\theta_{1}} .
\end{gathered}
$$

Total social surplus from trade in the scientific labor market is the area between the inverse labor supply curve and marginal social value curve up to the equilibrium quantity of labor. This surplus is equal to:

$$
\begin{aligned}
S^{*} & =\int_{0}^{L^{*}}\left[\frac{1}{\theta_{1}}\left(\theta_{0}-L\right)+z-\frac{1}{\phi_{1}}\left(L-\phi_{0}\right)\right] d L . \\
& =\left(\frac{\phi_{0} \theta_{1}+\phi_{1} \theta_{0}}{\phi_{1}+\theta_{1}}\right)\left[\left(\frac{\phi_{0} \theta_{1}+\phi_{1} \theta_{0}}{2 \phi_{1} \theta_{1}}\right)+z\right] .
\end{aligned}
$$

The total social surplus is given by the sum of areas A, B, and C in Figure 1. The existence of the positive externality means that the market equilibrium employment level is lower than the efficient (i.e., social-surplus-maximizing) level, where the latter is determined by the intersection between the labor supply curve and the marginal social value curve.

\subsection{Social surplus with immigration but with identical spillovers for domestic and immigrant scientists}

We next allow for positive immigration but initially assume that spillovers, $z$, are identical for domestic and immigrant scientists. We graph this case in Figure 2. The new equilibrium wage and employment levels are:

$$
w^{* *}=\frac{\theta_{0}-\phi_{0}-I}{\phi_{1}+\theta_{1}}
$$




$$
L^{* *}=\frac{\phi_{0} \theta_{1}+\phi_{1} \theta_{0}+\phi_{1} I}{\phi_{1}+\theta_{1}}
$$

It is also useful to identify the employment level of domestic scientists at the new equilibrium with immigration:

$$
L^{* * *}=\phi_{0}+\phi_{1} w^{* *}=\frac{\phi_{0} \theta_{1}+\phi_{1} \theta_{0}-\phi_{1} I}{\theta_{1}+\phi_{1}}
$$

Notice that the domestic displacement is equal to:

$$
L^{*}-L^{* * *}=\frac{\phi_{1}}{\phi_{1}+\theta_{1}} I
$$

There is no displacement if $\phi_{1}$ is equal to zero, so that the domestic labor supply is perfectly inelastic. To determine total social surplus, it is useful to separate out the surplus due to domestic versus immigrant scientists. Using Equation (10), the part due to domestic scientists is given by:

$$
\begin{aligned}
S_{\text {domestic }}^{* *} & =\int_{0}^{L^{* * *}}\left[\frac{1}{\theta_{1}}\left(\theta_{0}-L\right)+z-\frac{1}{\phi_{1}}\left(L-\phi_{0}\right)\right] d L \\
& =\left(\frac{\phi_{0} \theta_{1}+\phi_{1} \theta_{0}-\phi_{1} I}{\phi_{1}+\theta_{1}}\right)\left[\left(\frac{\phi_{0} \theta_{1}+\phi_{1} \theta_{0}}{2 \phi_{1} \theta_{1}}\right)+z+\frac{I}{2 \theta_{1}}\right] \\
& =S^{*}-\left(\frac{\phi_{1} z}{\phi_{1}+\theta_{1}}\right) I-\left(\frac{\phi_{1}}{2 \theta_{1}\left(\phi_{1}+\theta_{1}\right)}\right) I^{2},
\end{aligned}
$$

where the last line makes use of Equation (7).

Because we are taking the perspective of the welfare of the receiving country, we exclude the surplus accruing directly to immigrant scientists. Domestic social surplus accruing from immigrants is thus the difference between the marginal social value curve and the postimmigration wage line (Equation (8)), where it is assumed that immigrants are the marginal labor suppliers. This surplus is given by: 


$$
\begin{aligned}
S_{\text {immigrant }}^{* *} & \left.=\int_{L^{* * *}}^{L^{* *}}\left[\frac{1}{\theta_{1}}\left(\theta_{0}-L\right)+z-w^{* *}\right)\right] d L . \\
& =z I+\left(\frac{1}{2 \theta_{1}}\right) I^{2} .
\end{aligned}
$$

Total social surplus is found by summing the two components. After some cancellation, this yields:

$$
S_{\text {total }}^{* *}=S_{\text {domestic }}^{* *}+S_{\text {immigrant }}^{* *}=S^{*}+\left(\frac{\theta_{1} z}{\phi_{1}+\theta_{1}}\right) I+\left(\frac{1}{2\left(\phi_{1}+\theta_{1}\right)}\right) I^{2}
$$

Noting that total social surplus depends positively on both the level and the square of the level of immigration, the surplus is increasing at an increasing rate with the level of immigration. The size of the gain will also depend positively on the size of the per-unit spillover, $z$, with a positive interaction between the size of the spillover and the level of immigration. The gain in social surplus is shown by the area enclosed by the dark black line in Figure 2.

\subsection{Social surplus with immigration but with differential spillovers for domestic and immigrant scientists}

We next examine the case where the spillover from domestic scientists, $z^{D}(\geq 0)$, differs from the spillover from immigrant scientists, $z^{I}(\geq 0)$, where it is assumed that $z^{D} \geq z^{I}$. The total social surplus is now:

$$
S_{\text {total }}^{* *}=S_{\text {domestic }}^{* *}+S_{\text {immigrant }}^{* *}=S^{*}+\left(\frac{\theta_{1} z^{I}-\phi_{1}\left(z^{D}-z^{I}\right)}{\phi_{1}+\theta_{1}}\right) I+\left(\frac{1}{2\left(\phi_{1}+\theta_{1}\right)}\right) I^{2}
$$

Compared to the case of equal spillovers, an examination of Figure 3 shows a loss of social surplus on units that would have been supplied by domestic scientists in the absence 
of displacement. The lower spillovers from immigrant scientists also reduces the size of the gain from immigration, although there is still a direct gain in social surplus that is increasing non-linearly in the level of immigration. The overall impact on social surplus will depend on the relative sizes of these gains and losses. If the gap between $z^{D}$ and $z^{I}$ is large enough, it is possible that the displacement of domestic scientists reduces social surplus overall, notwithstanding the larger total size of the scientific workforce.

We now can identify from Equation (15) two distinct sufficient conditions for immigration not to reduce domestic social surplus given any level of immigration (i.e., for $S_{\text {total }}^{* *} \geq S^{*}$ ). First, there will be no harm if there is no domestic displacement, i.e., $\phi_{1}=0$. Second, and central to the empirical part of the paper, there will be no harm if there is no difference between the domestic and immigrant spillover, i.e., $z^{D}-z^{I}=0$.

Using Equation (15), we also can identify the necessary and sufficient condition for the absence of harm from immigration. This condition is:

$$
z^{I} \geq \frac{\phi_{1} z^{D}}{\left(\phi_{1}+\theta_{1}\right)}-\left(\frac{1}{2\left(\phi_{1}+\theta_{1}\right)}\right) I
$$

The "break-even" level of immigrant spillover is then the level of $z^{I}$ at which Equation (16) holds with equality. We graph the break-even in Figure 4 as a function of the level of immigration. The break-even level is declining in the level of immigration, reaching zero at an immigration level of $2 \phi_{1} z^{D}$. Given that the size of the immigrant spillover is assumed to be bounded from below at zero (i.e., the spillover is not negative), any immigration level above this level is associated with a net benefit regardless of the level of domestic displacement.

Summing up this section, we have found in the context of a simple market model with spillovers that it is possible that immigration harms domestic social welfare (as measured by the total surplus accruing to ex ante domestic residents from trade in the scientific labor market). This result requires both the displacement of domestic scientists by immigrants 
and lower spillovers from immigrants compared with domestic counterparts. However, the size of the spillover required from immigrant scientists to avoid immigration harming social welfare is decreasing in the level of immigration. Notwithstanding displacement effects, a sufficient condition for scientist immigration not to reduce ex ante domestic social welfare in the model is therefore an absence of differential spillovers.

As presented, the model applies to the general market for scientists. One could apply a narrower version to the segment of the market limited to employment at leading research universities. Displacement is then more naturally thought of as domestic scientists moving to lower-ranked universities, as found for example in Borjas and Doran (2012) as a result of the inflow of ex-Soviet mathematicians. In this case, we still would expect spillovers from displaced domestic scientists. However, if we assume that a faculty position in a leading university provides a privileged position in terms of the opportunities for relationship/network development $^{5}$ - and that domestic scientists are culturally or linguistically better positioned to take advantage of those opportunities - then downward institutional displacement could still be associated with a loss of aggregate spillovers and social welfare that again must be weighed against the direct gains from scientist immigration. The search for evidence on possible differential spillovers from domestic and immigrant scientists motivates the empirical work in the remainder of the paper.

\footnotetext{
${ }^{5}$ For example, positions at leading universities may provide faculty members with more graduate students. The pool of former graduate students then becomes a natural pool for matching with collaborators. In Agrawal et al. (2015), we develop a model in which scientists form the best match from the pool of former graduate students. Even where each potential former graduate student collaborator is drawn from a given uniform distribution, simply having more graduate students - and thus more draws - increases the expected value of collaboration. We then show that improvements in collaboration technology, which we assume to scale up the value of collaboration, are more valuable for scientists with more graduate students and thus more draws from which to find the best match.
} 


\section{The Prevalence and Impact of Immigrant Scientists on US Science}

Immigrant scientists make up a large and growing proportion of the US scientific workforce. Table 1 shows estimates of the size of the workforce in science occupations in 2003 and 2013. The estimates are drawn from the National Science Foundation's Scientists and Engineers Statistical Data System (SESTAT), which is in turn based on the National Survey of College Graduates (NSCG) and the Survey of Doctoral Recipients (SDR). Overall, immigrant scientists made up an estimated 22 percent of the US science workforce in 2003, rising to 27 percent in 2013. The largest immigrant percentages are in non-social science fields, with immigrants in 2013 comprising 29 percent of computer and mathematical scientists, 28 percent of biological, agricultural and environmental life scientists, and 25 percent of physical and related scientists. The largest increase in share over the period was for physical and related scientists, which rose from 20 percent in 2003 to 25 percent in 2013.

A significant literature has explored the performance of immigrant scientists and engineers

in the US labor market and also their impact on US economic performance. Hunt and Gauthier-Loiselle (2010) observe both positive direct and indirect effects of highly skilled immigrants on US innovation. Using the 2003 National Survey of College Graduates they find that immigrants patent at roughly double the rate of natives. A one percentage point increase in the college-educated immigrant share in the population leads to a six percent increase in patents per capita. However, they note that this could overstate the effects of immigration if there are displacement effects, or understate it if there are positive spillovers. Using a state-level analysis to correct for these biases, they find that a one percentage increase in the share of immigrant college graduates in the population leads to a 9-18 percent increase in patents per capita. Kerr and Lincoln (2010) find that cities and firms that disproportionately utilized $\mathrm{H}-1 \mathrm{~B}$ visa holders increased employment and patenting relative 
to peers. Peri (2012) finds evidence that immigrants to the US have increased total factor productivity. Combining various impacts, he finds that an increase in 1 percent in highskilled population in a state due to immigration, increases income per worker by 1 percent in that state. Peri et al. (2013) report that a H-1B driven increase in science, technology, engineering, and mathematics (STEM) workers increases the wages of both STEM and nonSTEM workers at the city level. Using data from the American Community Surveys of 2009 and 2010, Hunt (2015) finds that immigrant engineers that are successful in finding work in engineering occupations outperform the native-born based on both educational attainment and earnings. Piecing together various data sources, Stephan (2010) documents the high prevalence and impact of immigrant scientists at US Universities. A "conservative estimate" is that immigrants comprise "at least 25 percent of tenure-track faculty and make up over $43 \%$ of graduate students and 60 percent of post docs" (Stephan, 2010, p. 85). She also estimates that $44 \%$ of first authors on papers are immigrants. This impact is also apparent for the most prestigious publications; for example, 44 percent of first authors of US papers in Science are immigrants.

Recognizing that immigrant scientists may be less connected to other US scientists than the native-born counterparts they potentially displace, the focus of our empirical analysis is a hypothetical experiment in which an immigrant scientist is assumed to fully displace a matched US scientists with the same observed characteristics. Indirect evidence suggests that US scientists do successfully integrate into US-based knowledge networks. In an important paper, Ganguli (2015) finds that when Soviet-era scientists moved to the US, citations by US scientists to their Soviet-era work increased, indicating they were able to successfully form connections to the US-based scientific community.

A possible limitation of our approach is that a proportion of immigrant scientists come to the US as doctoral or post-doctoral students, and many of these will not have published prior to their move. We cannot identify these scientists as immigrants in our data set. 
However, it is reasonable to suppose that, due to their arrival at an early career stage, these scientists will be at least as well connected to US knowledge networks as those who come to the US after their publication career had started. The hypothetical full displacement effect should be lower for these scientists. Focusing on scientists who had begun their publishing career prior to emigrating should thus provide a reasonable upper bound on the size of the hypothetical displacement effect.

We finally reiterate that the assumption of full displacement of a US-born scientist is an extreme assumption. It is likely that the number of displaced scientists is less than the number of immigrants. Based on the findings of Borjas and Doran (2012), an empirically relevant but less dramatic mode of displacement is for the displaced US scientists to find employment at lower-ranked institutions or to less competitive fields Borjas and Doran (2015). To the extent that working at highly ranked institutions provides a privileged position of access to US knowledge networks and US-born scientists are better able to avail of the resulting opportunities for knowledge exchange, this form of displacement could also negatively impact on the performance of US science. However, such downward displacement should have less of an adverse effect than the full displacement baseline, again suggesting that the assumption of full displacement provides a reasonable estimated upper bound of the extent of harm through impaired US knowledge networks.

\section{Empirical Strategy}

In the model, a sufficient condition for the absence of harm is that the US scientific community draws equally from knowledge generated by foreign recruits as they do from knowledge generated by the domestic scientists the immigrants may displace. This holds true even with

full displacement. Our empirical strategy is to conduct a hypothetical experiment in which a foreign recruit displaces a matched domestic scientist, where we match scientists based 
on career age (years since first publication), productivity (number of citation-weighted publications), and field (six distinct fields described below). We then examine the number of citations from the US scientific community - our measure of localized knowledge flows - to immigrants compared to their matched domestic counterparts.

As a preliminary step, we first examine the number of citations from the US scientific community to immigrants before they move compared to their domestic matches. Next, turning our attention to how knowledge flows from immigrants to the US scientific community change over time, we compare the number of citations from the US scientific community to immigrants before versus after the immigrants move to the US. Finally, focusing on differential knowledge flows that may provide evidence of immigrant harm to US science - the core of our analysis - we examine the number of citations from the US scientific community to immigrants compared to their domestic matches. A finding of no difference would be consistent with the hypothesis of no harm to domestic science even with full displacement.

\section{$5 \quad$ Data and Matching Methodology}

Our primary objective is to compare spillover patterns between domestic and immigrant scientists. Thus, we must identify scientists, their type (domestic or immigrant), and their spillovers. We use publication data to do this. Our primary source is the ISI Web of Science (WoS). We begin by collecting publications in six fields: 1) evolutionary biology, 2) mathematics, 3) economics, 4) neuroscience, 5) immunology, and 6) psychology. We collect all publications in the journals classified by the ISI Journal Citation Reports as being associated with each of those fields. In Table 2, we list the number of journals associated with each field and the number of papers we collect from this set of journals over the period 1979-2008. In terms of the number of publications, neuroscience and immunology are the two largest fields (825,048 and 639,439 papers, respectively) and evolutionary biology and 
psychology are the two smallest (114,190 and 191,333 papers, respectively). We identify 9,641 scientists that immigrated into the US, which represents $4.1 \%$ of our sample of all active scientists across the globe. We present descriptive statistics of our star subsample in Table 3. For the star subsample, we identify 1,896 immigrant scientist who make up $10 \%$ of the sample of all global star scientists. This is consistent with the US attracting a disproportionate share of high-quality foreign born scientists.

Figure 5 presents a map showing the origins of all immigrant scientists in our sample. While the top 5 origin countries (in order: United Kingdom, Canada, Japan, Germany, and France) are responsible for over $58 \%$ of all US immigrant scientists, we observe emigration from a total of 69 countries in our sample.

\subsection{Identifying scientists}

We conduct most of our analyses at the scientist-year level. So, using the publication data described above, we identify the set of scientists in each of the six fields. One data challenge with this process is that WoS data do not provide unique identifiers for scientists. In other words, the data do not distinguish between two different people who have the same name. Thus, we must disambiguate scientific authors. To do so, we employ an approach developed by Tang and Walsh (2010). The heuristic utilizes backward citations of focal papers to estimate the likelihood of the named author being a particular person. For example, if two papers reference a higher number of the same papers (weighted by how many times the paper has been cited, i.e., how popular or obscure it is), then the likelihood of those two papers belonging to the same author is higher. We attribute two papers to the same author if both papers cite two or more rare papers (fewer than 50 citations) in both papers. We repeat this process for all papers that list non-unique author names (i.e., same first initial and last name). We exclude scientists who do not have more than two publications linked to their name. In Table 2, we list the number of unique scientists we identify in each field. Once 
again, immunology and neuroscience are the two largest fields (84,649 and 91,405 scientists, respectively). The two smallest fields are evolutionary biology and psychology (9,619 and 9,805 scientists, respectively). Scientists enter the panel when they publish their first paper. We identify their location and status (star or not) on an annual basis.

\subsection{Defining stars}

We define stars as scientists in the 90th percentile in a given year and discipline in terms of their accumulated stock of citation-weighted paper output over the preceding years. To calculate a scientist's accumulated stock of citation-weighted paper output, we begin by identifying the set of papers they published in the years preceding the focal year. We then weight these papers by the number of citations they receive during our study period. For example, if a scientist published four papers by 1990 and these papers received 10, 20, 15, and 40 citations by 2008 (the final year of our study period), then that scientist's accumulated stock of citation-weighted paper output would be 85 in 1990. While we define a scientist's contribution on an annual basis, our measure of stardom is time-invariant whereby we classify a scientist as a star if the scientist has ever been above the 90th percentile (approximately 15\% of scientists). ${ }^{6}$ Furthermore, stars are defined relative to the other scientists in our sample in the same discipline. When we do analyses of the full sample (across all disciplines), we utilize the star categorization determined from the within-field analysis. Although citation practices vary across fields, scientists in the 90th percentile are disproportionately more productive than the median scientist across all fields as seen in Figure 6.

\footnotetext{
${ }^{6}$ Results are very similar if we conduct our analyses using a time-varying definition of star scientists whereby we only classify scientists as stars in years in which their stock of citation-weighted paper output exceeds the 90th percentile.
} 


\subsection{Identifying scientist locations}

Using the unique author identifiers generated in the process described above for each paper, we then attribute each scientist to a particular institution for every year of activity. Scientists are active from the year they publish their first paper to the year they publish their last paper. Here again, we must overcome a data deficiency inherent within the WoS data; until recently, the WoS did not link institutions listed on an article to the authors. Instead, we impute author location using reprint information that provides a one-to-one mapping between the reprint author and the scientist's affiliation. In addition, we take advantage of single institution publications that allow us to directly link authors to institutions.

\subsection{Defining immigration}

With information on each scientist's location in each year, we identify the country of each scientist's institution. Domestic scientists are those who start their career in the US and never emigrate. Immigrant scientists are those who start their career in a country other than the US and some year after their first publication immigrate to the US.

\subsection{Outcome measure}

Our outcome measure of interest is knowledge flows. We identify all papers published by the focal scientist in the focal year for each scientist-year. From this set of papers, we count the number of forward citations (citations made to the focal paper by other papers in the future). We classify each forward citation as domestic if the first author of the future paper that references the focal paper is from the US and not-domestic otherwise.

While a large literature exists on the localization of knowledge flows (Feldman, 2000; Ganguli, 2015), we choose to circumscribe the flow of citations at national borders for two reasons. First, this study directly speaks to the debate in immigration policy which is set at 
the national level. The US federal government as an entity cares about growing the spillover "pie" within the US and is less concerned about how the benefits of this pie are allocated across space within the US, per se. Second, and relatedly, federal science funding also adopts a very similar model by which it cares about advancing the US scientific enterprise in aggregate and is less focused on distributional concerns.

\subsection{Matching}

Immigrant and domestic scientists may systematically differ along a range of dimensions hindering insightful comparisons between the two groups. As such, we identify a subset of both immigrant and domestic scientists who are on the common support of a vector of covariates related to scientific productivity in the year of the immigrant's move to the US. More specifically, for all immigrant scientists who immigrate to the US in year $t$, we identify a domestic scientist match in year $t$ who is in the same field, has a similar quality-weighted stock of publications, was equally as productive in year $t$, and has a similar career age. ${ }^{7}$ We make use of the of the Coarsened Exact Matching (CEM) methodology first developed by Iacus et al. (2012). Table 4 shows balance between immigrant and domestic scientists of our matched covariates across both the full and star sample.

\section{Results}

\subsection{Comparisons of matched pairs}

Our knowledge flow measure is the number of times the US scientific community cites the focal scientist. Under the hypothetical scenario of full displacement of an equivalent domestic

\footnotetext{
${ }^{7}$ By making use of publication data to infer scientist location, we consequently also use publication data to infer mobility. That is, we can only identify the first year that a scientist immigrated to the US in the year that they first published a paper in the US.
} 
scientist, we test for significant differences between the number of citations to the work of the immigrant and their (hypothetically displaced) domestic match. We look at all immigrants and also, separately, the subset of immigrant stars.

For each sample, we make three distinct comparisons. First, we compare pre-move immigrants with their domestic matches. This allows us to understand spillover differentials to the US scientific community before the move takes place. Second, we compare pre- and post-move immigrants. This allows us to understand the way the immigrant's connection to US science changes upon moving to the US. Third, we compare post-move immigrants with their domestic matches. This is our main comparison, and it allows us to understand how localized knowledge flows would be affected even with full displacement of an equivalent domestic scientist.

In Figure 7 we provide a graphical depiction of all three comparisons and also compare across the full and star samples. The general picture that emerges is that pre-move immigrants produce significantly less knowledge flows to the US scientific community than their domestic matches. However, this gap tends to disappear with the move as immigrants appear to quite rapidly integrate with the US scientific community. Post move, the number of citations from the US scientific community to the immigrants' work is at least as large as to their domestic matches.

Tables 5 and 6 provide formal tests for our three comparisons for the full and star-only samples, respectively. The top panel of each table compares pre-move immigrants with their domestic matches. We look separately at total citations, US citations, and the share of US citations of total citations. Indicating the success of the matching procedure, there is no significant difference in total citations for the immigrants and their domestic matches. However, the domestic matches have significantly higher US citations and higher shares of US citations in total citations. This difference is particularly pronounced for the star sample, where on average domestic matches receive more than 10 additional citations from the US 
scientific community compared to pre-move immigrants.

The bottom panel of each table tests for differences in citations to the work of immigrants pre- and post-move. Post-move immigrants receive significantly more total citations and US citations and also receive a higher share of US citations of their total citations for both the full and star-only samples.

The middle panel of each table compares post-move immigrants with their domestic matches - our central comparison. Post-move immigrants receive a larger number of citations from the US scientific community compared to their domestic matches (difference in full sample $=0.47, \mathrm{p}$-value $=0.15 ;$ difference in star sample $=2.58, \mathrm{p}$-value $=0.06)$. While domestic matches still display a higher share of US citations to their total citations, the difference is not statistically significant.

Overall, using citations as our measure, immigrants are found to produce at least an equivalent level of knowledge flows to the US scientific community as the matched domestic scientists who they hypothetically displace. At least by this measure, there is no evidence that scientist immigration would harm US science even with full displacement.

\subsection{Factors mediating the integration of immigrant scientists into US science}

Recognizing that not all immigrant scientists will be equally well-positioned to generate knowledge flows for the US scientific community, we next explore how sensitive our main result is to plausible factors mediating the connection of immigrants to US science networks. Where a factor is plausibly linked to a weaker (stronger) relationship to US scientists, a finding of a smaller (larger) "immigrant premium" gives us greater confidence that the difference between the matched pairs provides a meaningful measure of different spillover potential between immigrants and the domestic scientists they (hypothetically) displace. 
We examine two candidate-mediating factors. The first is the prevalence of co-nationals at the destination institution. A higher prevalence of co-nationals is likely to be associated with more limited connections to US scientists (McPherson et al., 2001). Such differential integration is supported by findings that co-ethnicity supports knowledge flows (see, e.g., Agrawal et al., 2008), so that the close proximity of co-nationals could reduce the incentive for the immigrant to form connections with US scientists. The second is where the use of English is common in the immigrant's country of origin. Proficiency in English should be positively associated with the ability of the immigrant to connect with US scientists. A large literature has documented that proficiency in English is positively associated with success in English-speaking destination-country labour markets (see, e.g., Chiswick and Miller, 1995; Dustmann and Fabbri, 2003).

We show the results of these difference-in-difference analyses in Tables 7 and 8 . We focus in particular on the difference in post-move US cites between immigrants and their domestic matches for both the full and star samples (Columns 2 and 5). In Table 7, we first compare the size of this "immigrant premium" when the immigrants have at most a single diaspora colleague with the case where they have two or more such colleagues. For the full sample, when immigrants are relatively isolated, there is a statistically significant positive immigrant premium; but there is a statistically significant negative premium (or discount) when the immigrant is co-located with two or more diaspora colleagues. The null of no difference between these premiums is strongly rejected $(\mathrm{p}$-value $=0.001)$. For the star sample, the size of the positive premium for the relatively isolated immigrants is even more pronounced than in the full sample. However, the effect is not statistically significant when there are two or more diaspora colleagues. The null of no difference between these premiums is again strongly rejected $(\mathrm{p}$-value $=0.001)$.

In Table 8 we repeat these comparisons of the "immigrant premium" based on whether the immigrant comes from a country where the use of English is common or not. For the full 
sample, the premium is only marginally statistically significant where the immigrant comes from a country where English is common. However, there is no statistically significant effect for immigrants from countries where english is uncommon. The p-value for the null of no difference between the two cases is 0.072. Interestingly, for the star sample, we cannot reject the null of no difference between the two cases $(\mathrm{p}$-value $=0.251)$. This may reflect the fact that strong English ability is common among stars regardless of whether they come from a country where the use of English is common or not.

Overall, the results of these difference-in-difference analyses are generally consistent with our priors. Immigrant scientists tend to perform better in terms of connections to US science when they are relatively isolated from co-nationals and also come from countries where the use of English is common, although the latter effect is not evident for stars.

\section{Concluding Comments}

The search for evidence of native wage and employment displacement effects has been a major theme of the immigration literature. More recently, in an attempt to better identify the benefits of high-skilled immigration, more attention has focused on knowledge spillovers to native workers. But this raises a new possibility of harm if local knowledge networks are disrupted by arrivals who displace domestic workers who are better embedded in knowledgesharing networks. To explore the possibility of such displacement, we use citation patterns to answer a simple question: Are immigrant scientists less connected to the US scientific community than the domestic scientists they displace? We find that although immigrant scientists are significantly less connected than their domestic matches pre-immigration, convergence is rapid post-immigration. Overall, we do not find evidence of harm to domestic science through a knowledge network disruption channel.

We conclude by noting some possible limitations of our findings and important areas 
for further research. First, while we use state-of-the-art matching techniques to identify our domestic matches for immigrant scientists, there is an inevitable residual concern that actual scientists displaced by immigrant arrivals are better connected to domestic scientists than these identified matches. It may also be that universities engaged in recruiting immigrant scientists are selecting those who are most likely to increase their productivity after arrival, increasing both the total knowledge spillovers they produce and also those that flow to the US.

Second, while we believe that forward citations provide the best measure of knowledge connections between scientists, other possibilities exist. One alternative is co-authorships with US scientists. Preliminary results suggest that immigrant scientists have fewer postarrival co-authorship relationships with US scientists than their domestic matches. But conditional on a co-authorship relationship with a US scientist, the quality of the output as measured by forward citations to the work is higher for immigrant-domestic collaborations. The nature of this quantity/quality tradeoff and also the relative importance of citation and co-authorship metrics as measures of connections between scientists requires further exploration.

Third, the diaspora and English-language results point to the kind of variables that mediate the integration of immigrant scientists into US knowledge networks. More work is needed to better understand the integration process and the public or organizational policies that might facilitate it.

Finally, although scientists who publish are a key component of US knowledge networks, further work is required to confirm that immigration-related network disruption effects do not cause greater harm in other knowledge sectors. An advantage of examining scientific papers is that a natural paper trail of connections is provided through citation patterns. Patent citations may allow for an extension of the approach used here to explore network disruption effects in other parts of the US knowledge system. 


\section{References}

Agrawal, Ajay, Devesh Kapur, and John McHale, "How do spatial and social proximity influence knowledge flows? Evidence from patent data," Journal of Urban Economics, 2008, 64 (2), $258-269$.

- Iain Cockburn, and John McHale, "Gone but not forgotten: Knowledge flows, labor mobility, and enduring social relationships," Journal of Economics Geography, 2006, 6 (5), 571591.

_ , John McHale, and Alexander Oettl, "Collaboration, Stars, and the Changing Organization of Science: Evidence from Evolutionary Biology," in "The changing frontier: rethinking science and innovation policy," The University of Chicago Press, Chicago, October 2015. University of Toronto mimeo.

Azoulay, Pierre, Joshua Graff Zivin, and Jialan Wang, "Superstar Extinction," Quarterly Journal of Economics, 2010, 125 (2), 549-589.

Borjas, George, "The Labor-Market Impact of High-Skill Immigration," The American Economic Review, 2005, 95 (2), 56-60.

_, "Do Foreign Students Crowd Out Native Students from Graduate Programs," in Ronald G. Ehrenberg and Paula E. Stephan, eds., Science and the University, University of Wisconsin Press, Madison, 2007.

- and Kirk B Doran, "The Collapse of the Soviet Union and the Productivity of American Mathematicians*," The Quarterly Journal of Economics, 2012, 127 (3), 1143-1203.

Borjas, George J, Immigration economics, Harvard University Press, 2014.

- and Kirk B Doran, "Cognitive mobility: Labor market responses to supply shocks in the space of ideas," Journal of Labor Economics, 2015, 33 (S1), S109-S145.

Chiswick, Barry R and Paul W Miller, "The endogeneity between language and earnings: International analyses," Journal of labor economics, 1995, 13 (2), 246-288.

Dustmann, Christian and Francesca Fabbri, "Language proficiency and labour market performance of immigrants in the UK," The Economic Journal, 2003, 113 (489), 695-717.

Feldman, Maryann P, "Location and innovation: the new economic geography of innovation, spillovers, and agglomeration," The Oxford handbook of economic geography, 2000, 1, 373-395.

Freeman, Richard, Ina Ganguli, and Raviv Murciano-Goroff, "Why and Wherefore of Increased Scientific Collaboration," in "The changing frontier: rethinking science and innovation policy," The University of Chicago Press, Chicago, 2015.

Ganguli, Ina, "Immigration and Ideas: What Did Russian Scientists "Bring" to the United States?," Journal of Labor Economics, 2015, 33 (S1), S257-S288. 
Hunt, Jennifer, "Are Immigrants the Most Skilled US Computer and Engineering Workers?, Journal of Labor Economics, 2015, 33 (S1), S39-S77.

- and Marjolaine Gauthier-Loiselle, "How Much Does Immigration Boost Innovation?" American Economic Journal: Macroeconomics, 2010, 2 (2), 31-56.

Iacus, Stefano M., Gary King, and Giuseppe Porro, "Causal Inference without Balance Checking: Coarsened Exact Matching," Political Analysis, 2012, 20 (1), 1-24.

Jaffe, Adam B., Manuel Trajtenberg, and Rebecca Henderson, "Geographic Localization of Knowledge Spillovers as Evidenced by Patent Citations," Quarterly Journal of Economics, August 1993, 108 (3), 577-598.

Kerr, Sari Pekkala and William R Kerr, "Economic impacts of immigration: A survey," Finnish Economic Papers, Finnish Economic Association 1-32, Spring 2011, 24 (1), 1-32.

Kerr, William R and William F Lincoln, "The Supply Side of Innovation: H-1B Visa Reforms and US Ethnic Invention," Journal of Labor Economics, 2010, 28 (3), 473-508.

Lan, Flora, Katherine Hale, and Emilda Rivers, "Immigrants' Growing Presence in the U.S. Science and Engineering Workforce: Education and Employment Characteristics in 2013," NSF 15-328, National Science Foundation 2015.

McPherson, Miller, Lynn Smith-Lovin, and James M Cook, "Birds of a feather: Homophily in social networks," Annual review of sociology, 2001, 27 (1), 415-444.

National Academies of Sciences, Engineering, and Medicine, The Economic and Fiscal Consequences of Immigration, The National Academies Press, Washington, DC, 2016.

Oettl, Alexander, "Reconceptualizing stars: Scientist helpfulness and peer performance," Management Science, 2012, 58 (6), 1122-1140.

Peri, Giovanni, "The effect of immigration on productivity: Evidence from US states," Review of Economics and Statistics, 2012, 94 (1), 348-358.

_, Kevin Shih, and Chad Sparber, "STEM workers, H1B Visas and Productivity in US Cities," 2013. Working Paper.

Stephan, Paula, "The "I" s have it: Immigration and innovation, the perspective from academe," Innovation Policy and the Economy, 2010, 10 (1), 83-127.

_, How Economics Shapes Science, Cambridge: Harvard University Press, 2012.

Tang, Li and John P Walsh, "Bibliometric fingerprints: Name disambiguation based on approximate structure equivalence of cognitive maps," Scientometrics, 2010, 84 (3), 763-784.

Thompson, Peter and Melanie Fox-Kean, "Patent citations and the geography of knowledge spillovers: A reassessment," American Economic Review, 2005, 95 (1), 450-460.

Waldinger, Fabian, "Quality matters: The expulsion of professors and the consequences for PhD student outcomes in Nazi Germany," Journal of Political Economy, 2010, 118 (4), 787-831. 
Figure 1: Market Equilibrium and Total Social Surplus, No Immigration

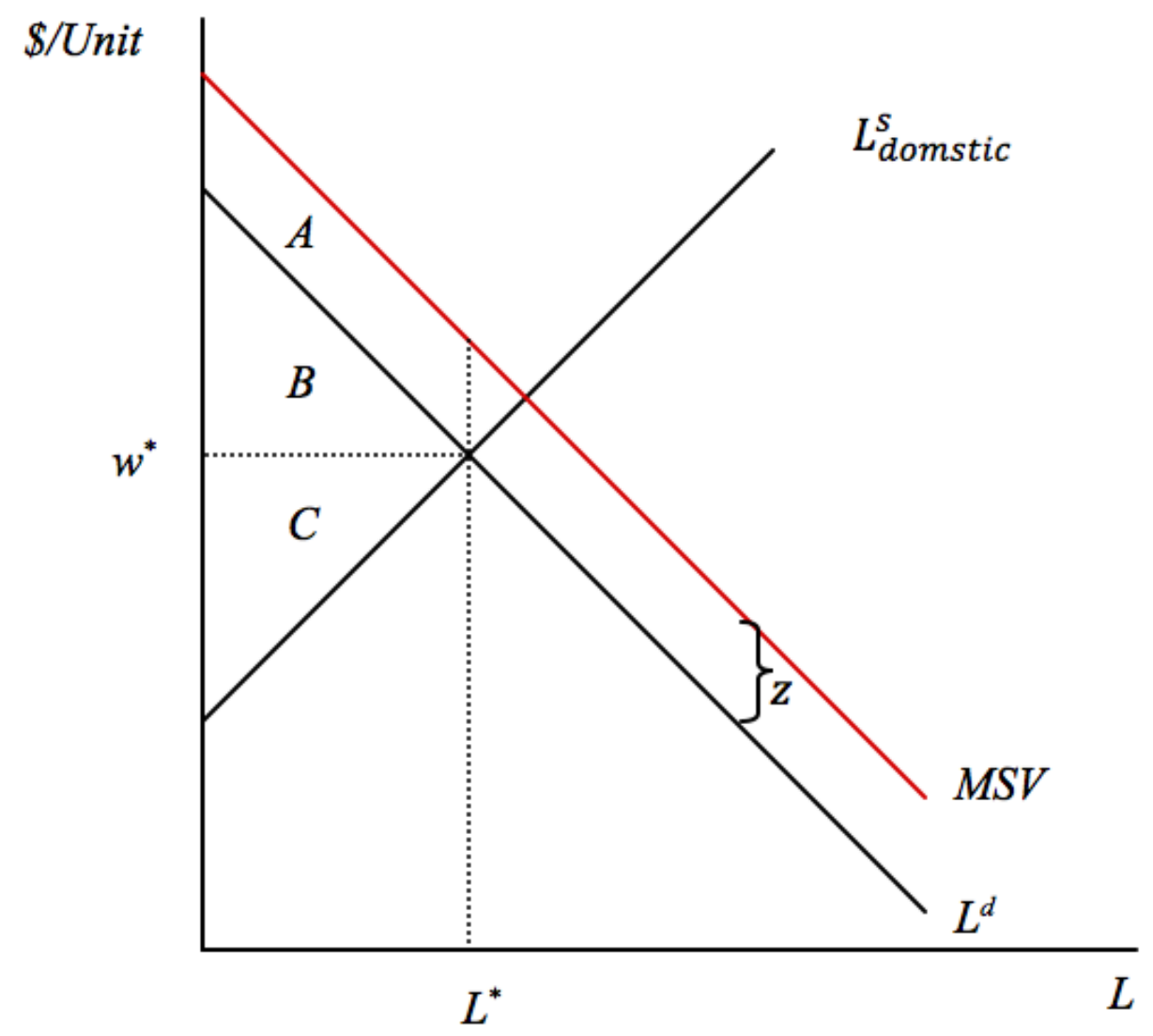


Figure 2: Market Equilibrium and the Gain in Social Surplus from Immigration

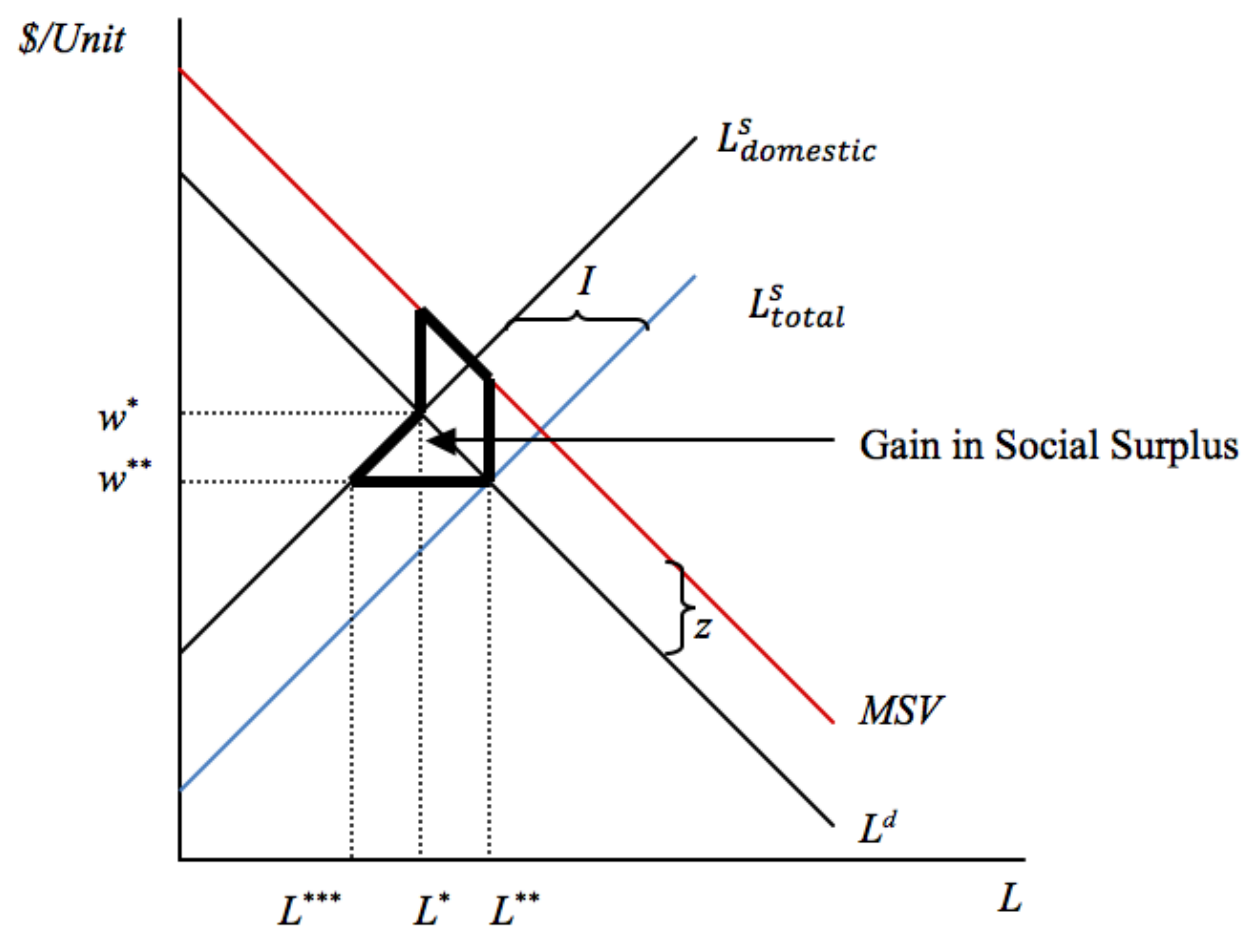

Note: The per-scientist externality is assumed to be equal to $z$ for domestic and immigrant scientists. 
Figure 3: Market Equilibrium and the Gain and Loss of Social Surplus when the per Scientist Externality is Lower for Immigrant Scientists

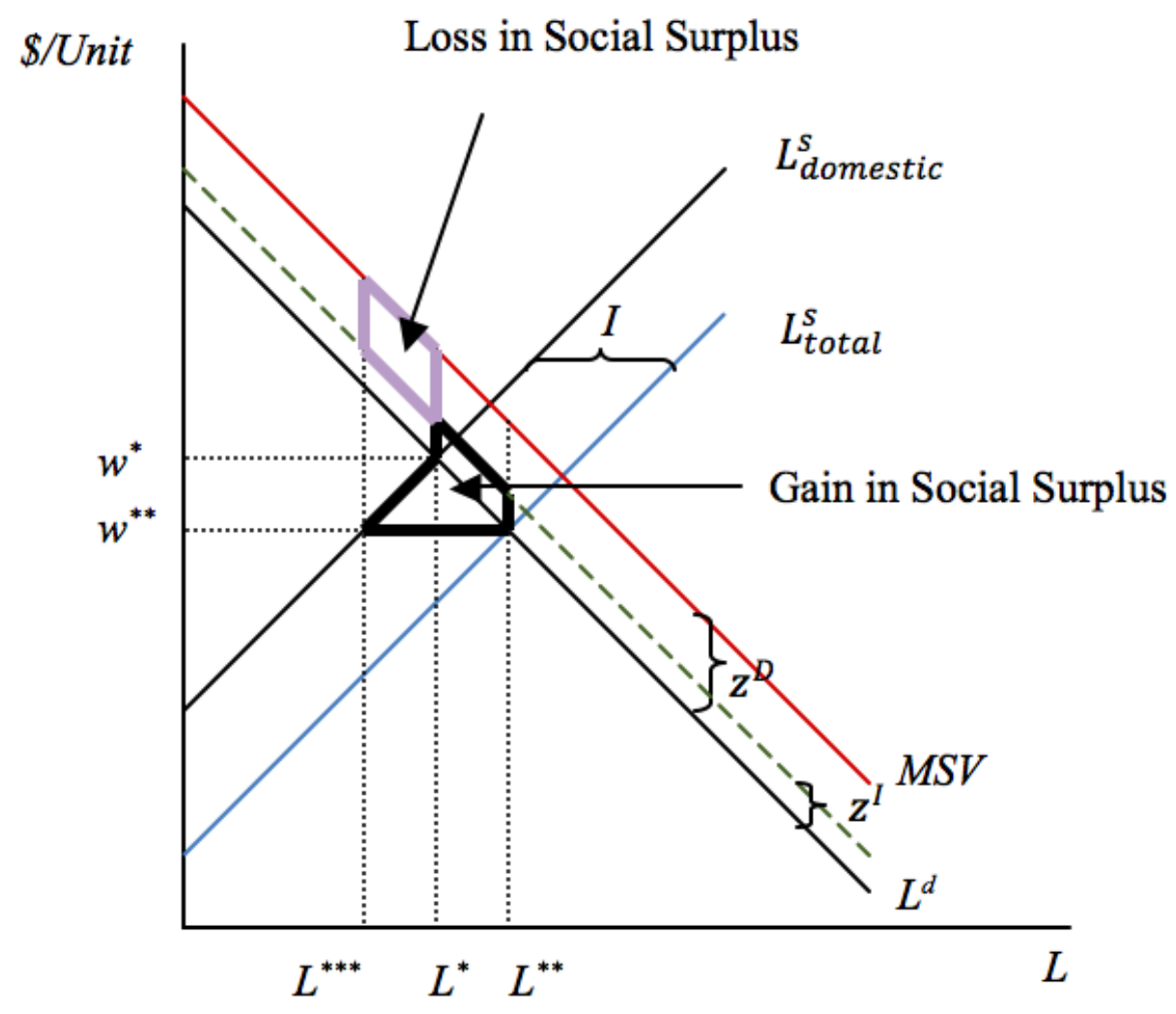


Figure 4: The Level of the Per-Scientist Externality for Immigrant Scientists for No Change in Social Surplus to Occur as a Result of Immigration

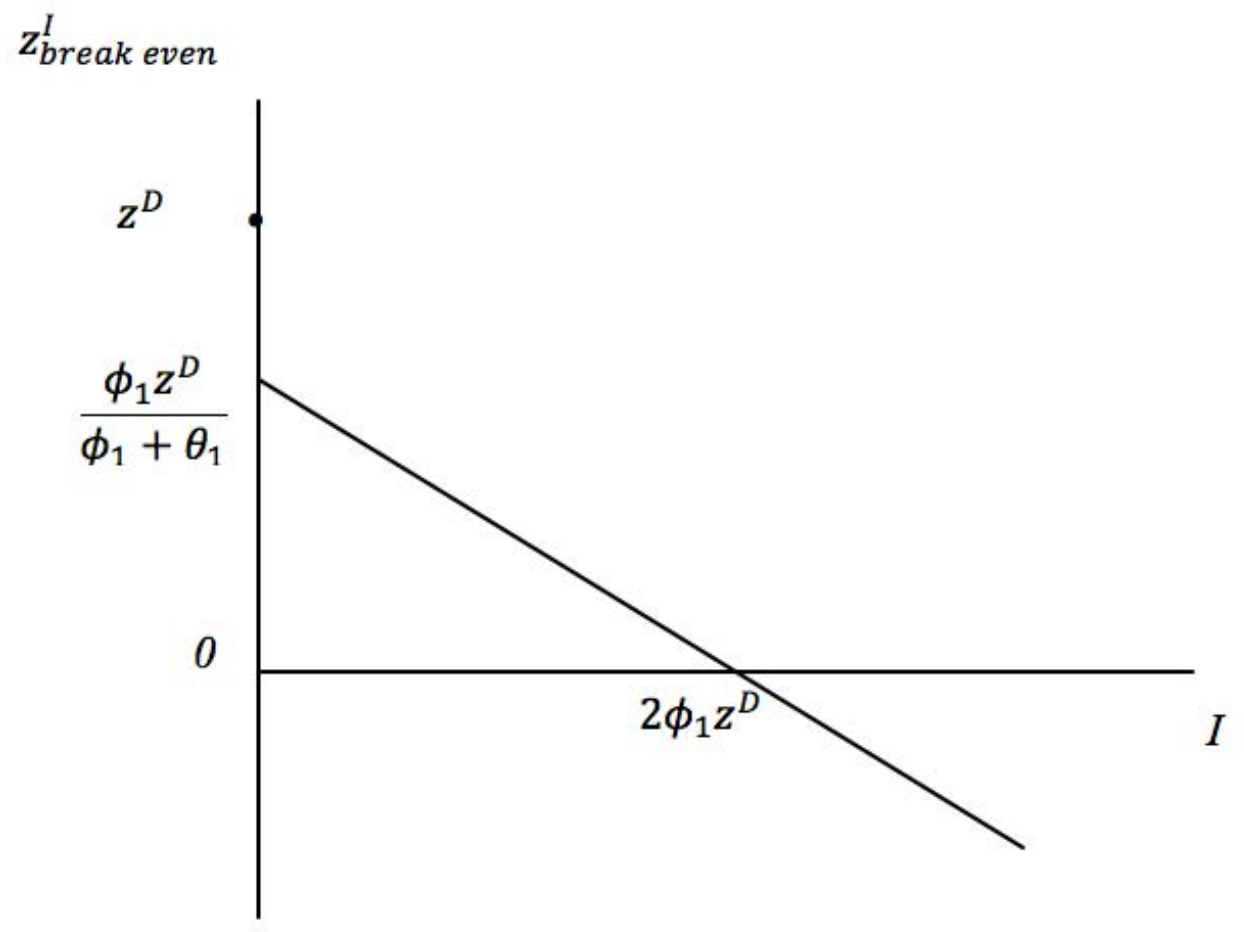




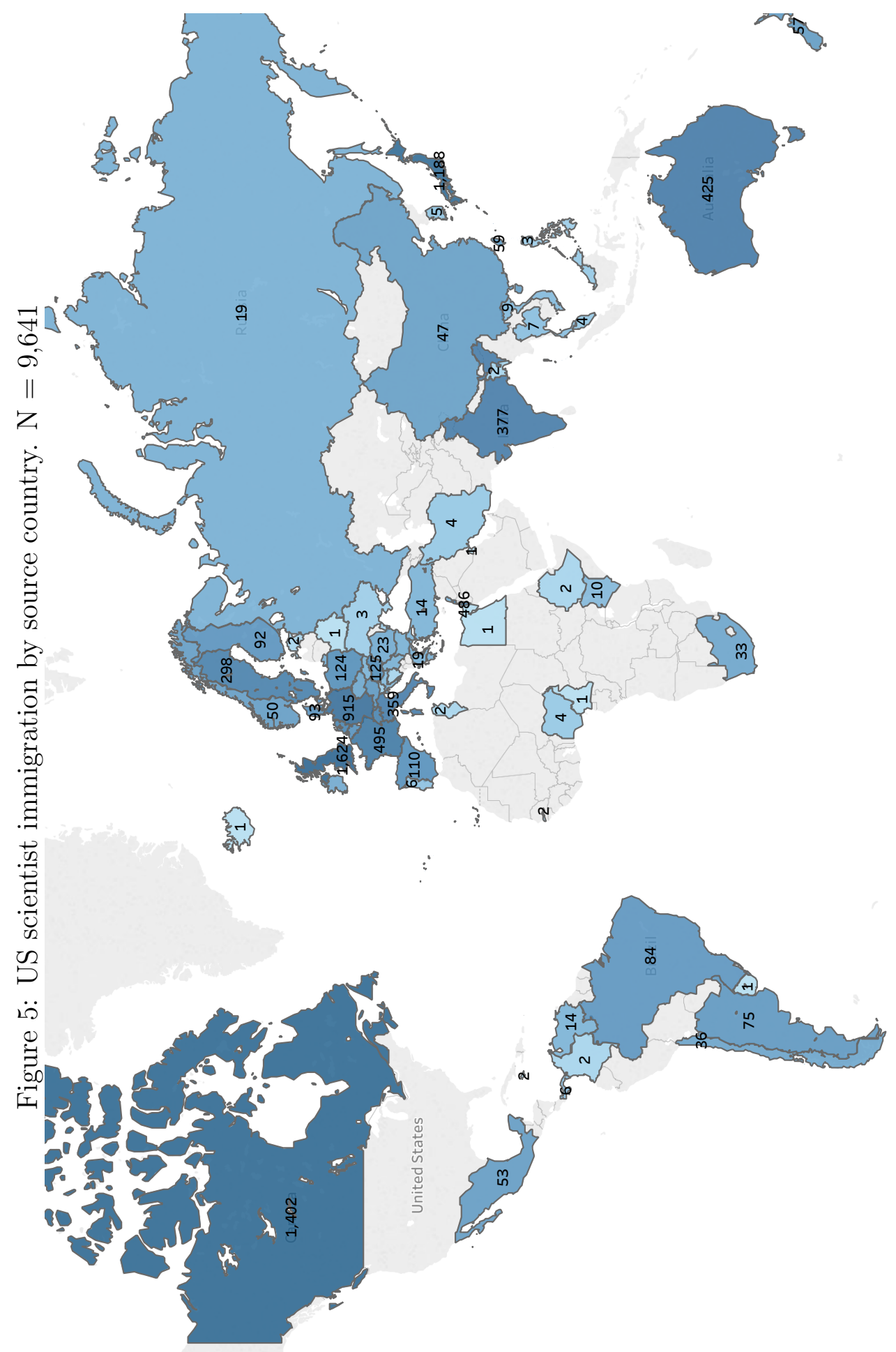


Figure 6: Citation Stock by Percentiles and Field in 1995

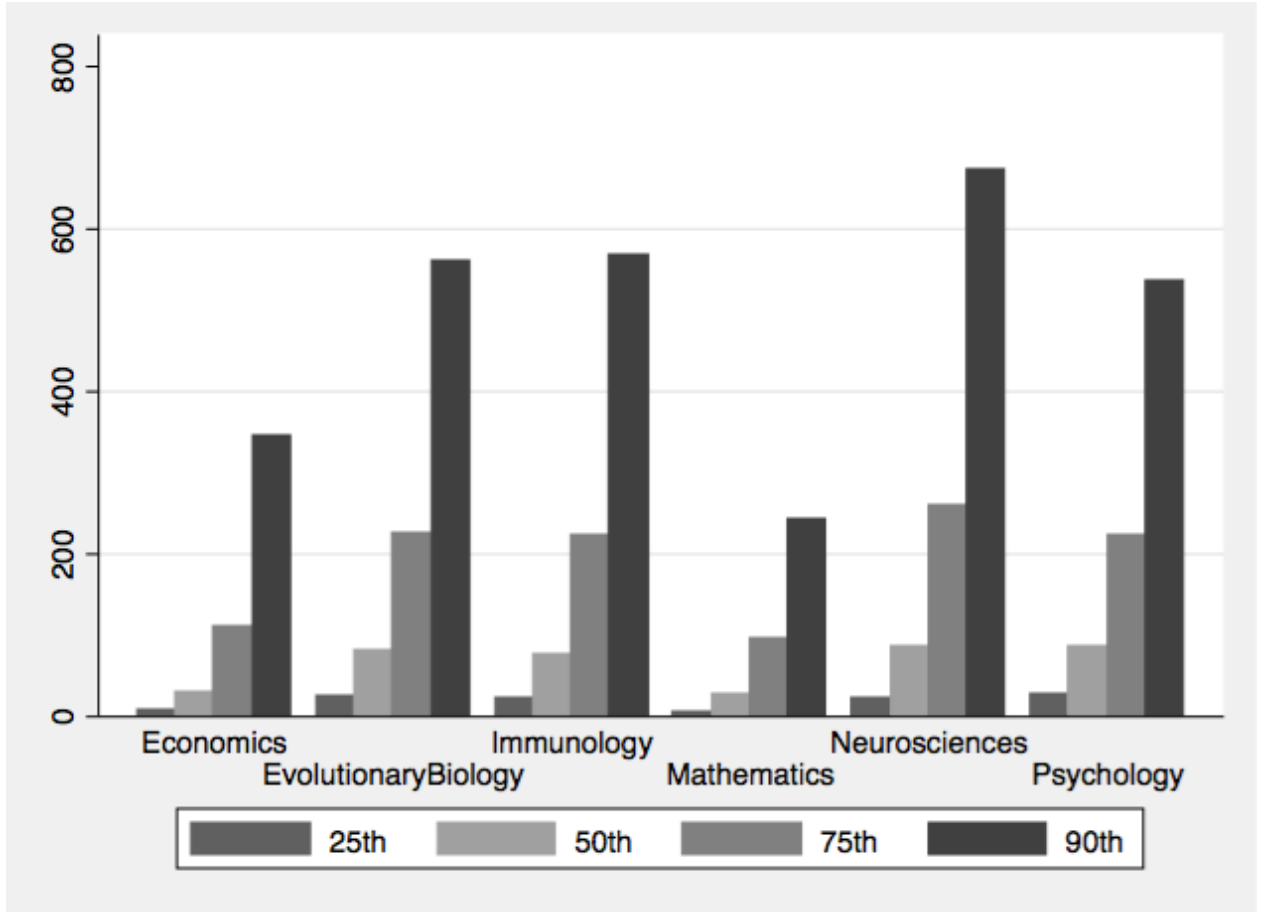

Figure 7: Number of US Citations: Immigrants relative to Domestics

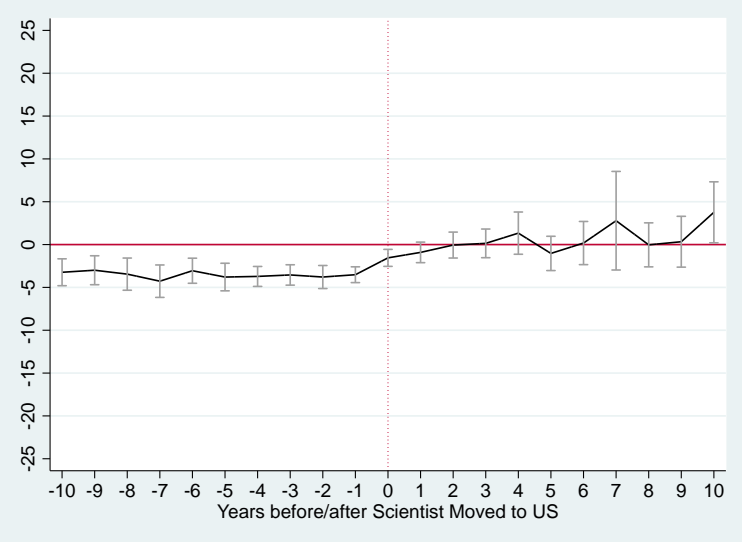

(a) Full Sample

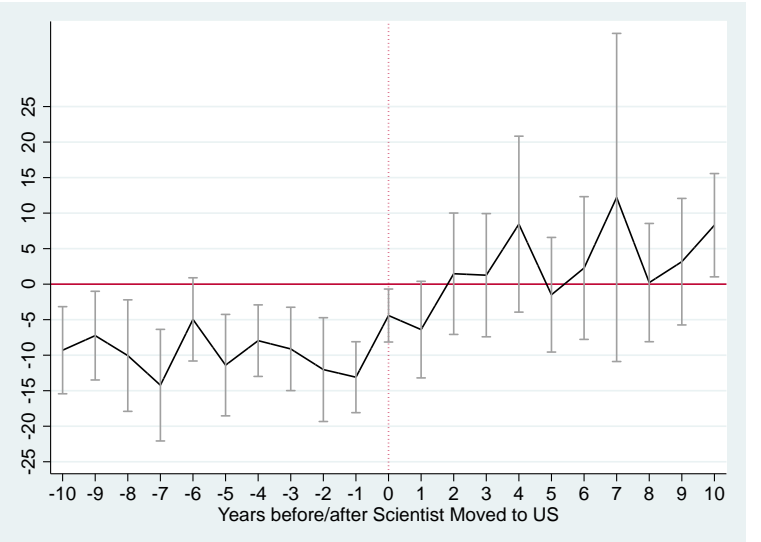

(b) Star Sample

Notes: This figure plots point estimates for leading and lagging indicators for the migration of a scientist to the US. Both panels plot the point estimates of the following specification estimated using OLS: USCitations $s_{i t}=\sum_{\tau=0}^{10} \alpha_{-\tau}$ Arrival $_{i, t-\tau}+$ $\sum_{\tau=1}^{10} \alpha_{+\tau}$ Arrival $_{i, t+\tau}+\sum_{\tau=0}^{10} \beta_{-\tau}$ Arrival $_{i, t-\tau} \times$ immigrant $_{i}+\sum_{\tau=1}^{10} \beta_{+\tau}$ Arrival $_{i, t+\tau} \times$ immigrant $_{i}+\theta\left(\right.$ Age $\left._{i t}\right)+\delta_{t}+\varepsilon_{i t}$. $U S$ Citations $_{i t}$ is the number of citations received by scientist $i$ in year $t$ from US-authored papers. The $\alpha$ parameters (21 in all) controls for the US citation patterns of the matched domestic scientists for each year 10 years prior and post to the matched immigrants arrival. The $\beta$ parameters are our point estimates of interest and are the ones plotted in the above figure. These reflect the differences in US citation patterns between immigrants and domestic scientists for each year around the move year (+/- 10 years). $\theta$ flexible controls for scientist $i$ 's age and $\delta$ is a full set of year dummies. There is no constant in this specification. The vertical bars correspond to $95 \%$ confidence intervals with scientist-clustered standard errors. 


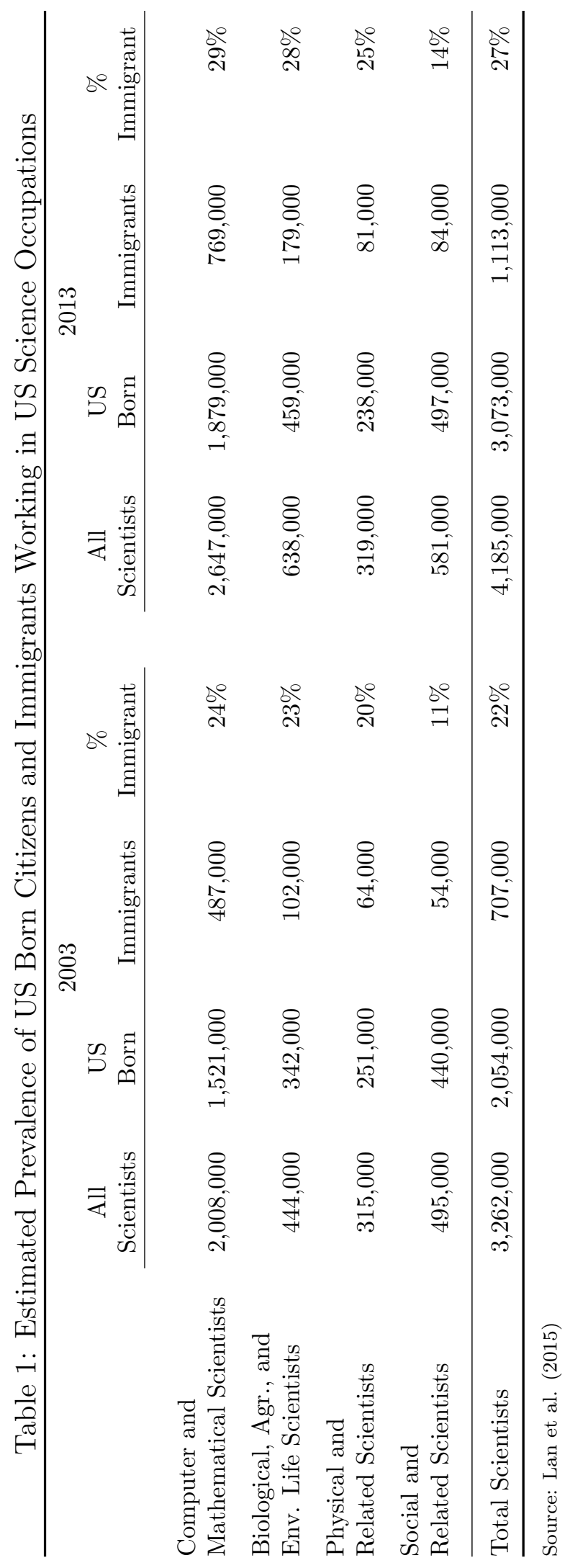


Table 2: Descriptive Statistics

\begin{tabular}{|c|c|c|c|c|c|c|c|}
\hline Discipline & Journals & Papers & Scientists & Domestics & Immigrants & $\begin{array}{c}\text { Citations/ } \\
\text { Scientist/ } \\
\text { Year }\end{array}$ & $\begin{array}{c}\text { Coauthors/ } \\
\text { Scientist/ } \\
\text { Year }\end{array}$ \\
\hline Economics & 214 & 105,305 & 18,466 & 10,302 & 552 & 8.38 & 0.39 \\
\hline Evol. Biology & 42 & 55,035 & 9,619 & 4,497 & 286 & 18.76 & 0.74 \\
\hline Immunology & 175 & 586,424 & 84,649 & 35,281 & 3,311 & 16.17 & 2.59 \\
\hline Mathematics & 190 & 126,535 & 22,156 & 7,644 & 1,065 & 3.67 & 0.42 \\
\hline Neuroscience & 247 & 678,572 & 91,405 & 38,074 & 4,209 & 19.14 & 2.14 \\
\hline Psychology & 71 & 49,316 & 9,805 & 5,495 & 218 & 6.9 & 0.67 \\
\hline Total & 939 & $1,601,187$ & 236,100 & 101,293 & 9,641 & $12.17^{\dagger}$ & $1.16^{\dagger}$ \\
\hline
\end{tabular}

Notes: Scientists refers to the total number of scientists active in the world. Domestics refers to the number of US-based scientists who started their careers in the US. Immigrants refers to the number of US-based scientists who emigrated to the US. Note that Domestics and Immigrants do not sum to Scientists because we do not report counts of scientists in the rest of the world who do not emigrate to the US during our study period. The last two columns count the mean number of citations received / unique coauthors per scientist per year.

$\dagger$ Means, instead of sums, are reported for these two columns.

Table 3: Descriptive Statistics (Star Sample)

\begin{tabular}{lrrrrrrr}
\hline \multicolumn{1}{c}{ Discipline } & Journals & Papers & Scientists & Domestics & Immigrants & $\begin{array}{c}\text { Citations/ } \\
\text { Scientist/ } \\
\text { Year }\end{array}$ & $\begin{array}{c}\text { Coauthors/ } \\
\text { Scientist/ } \\
\text { Year }\end{array}$ \\
\hline Economics & 214 & 29,727 & 1,324 & 1,058 & 101 & 34.45 & 0.72 \\
Evol. Biology & 42 & 14,866 & 755 & 458 & 49 & 59.72 & 1.21 \\
Immunology & 175 & 131,385 & 7,220 & 4,094 & 687 & 53.71 & 4.71 \\
Mathematics & 190 & 39,369 & 1,653 & 893 & 214 & 12.06 & 0.76 \\
Neuroscience & 247 & 144,420 & 7,129 & 3,902 & 799 & 61.72 & 3.83 \\
Psychology & 71 & 16,530 & 801 & 548 & 46 & 20.58 & 1.00 \\
\hline Total & 939 & 376,297 & 18,882 & 10,953 & 1,896 & $49.69^{\dagger}$ & $3.34^{\dagger}$ \\
\hline
\end{tabular}

Notes: Scientists refers to the total number of scientists active in the world. Domestics refers to the number of US-based scientists who started their careers in the US. Immigrants refers to the number of US-based scientists who emigrated to the US. Note that Domestics and Immigrants do not sum to Scientists because we do not report counts of scientists in the rest of the world who do not emigrate to the US during our study period. The last two columns count the mean number of citations received / unique coauthors per scientist per year.

$\dagger$ Means, instead of sums, are reported for these two columns. 
Table 4: Descriptive Statistics of Matched Domestic and Immigrant Scientists

\begin{tabular}{lrrrr}
\hline & $\begin{array}{r}\text { Domestic } \\
\text { Scientists } \\
\text { mean }\end{array}$ & $\begin{array}{r}\text { Immigrant } \\
\text { Scientists } \\
\text { mean }\end{array}$ & difference & p-value of difference \\
\hline Pariable & & & & \\
Career Age $A$ & 7.43 & 7.48 & -0.05 & 0.73 \\
Ever a Star & 0.14 & 0.14 & 0 & 1 \\
$\sum^{t-1}$ Cites & 154.11 & 153.92 & 0.19 & 0.97 \\
Cites & 34.36 & 35.19 & -0.83 & 0.37 \\
\hline Observations & 4,623 & 4,623 & & 0.79 \\
\hline \hline Panel B: Star Sample & & & & 1 \\
Career Age & 9.99 & 10.1 & -0.11 & 0.78 \\
Ever a Star & 1 & 1 & 0 & 0.54 \\
$\sum^{t-1}$ Cites & 449.9 & 442.67 & 7.23 & \\
\hline Obites & 78.7 & 80.83 & -2.13 & \\
\hline
\end{tabular}

Table 5: Mean Comparisons of Citations

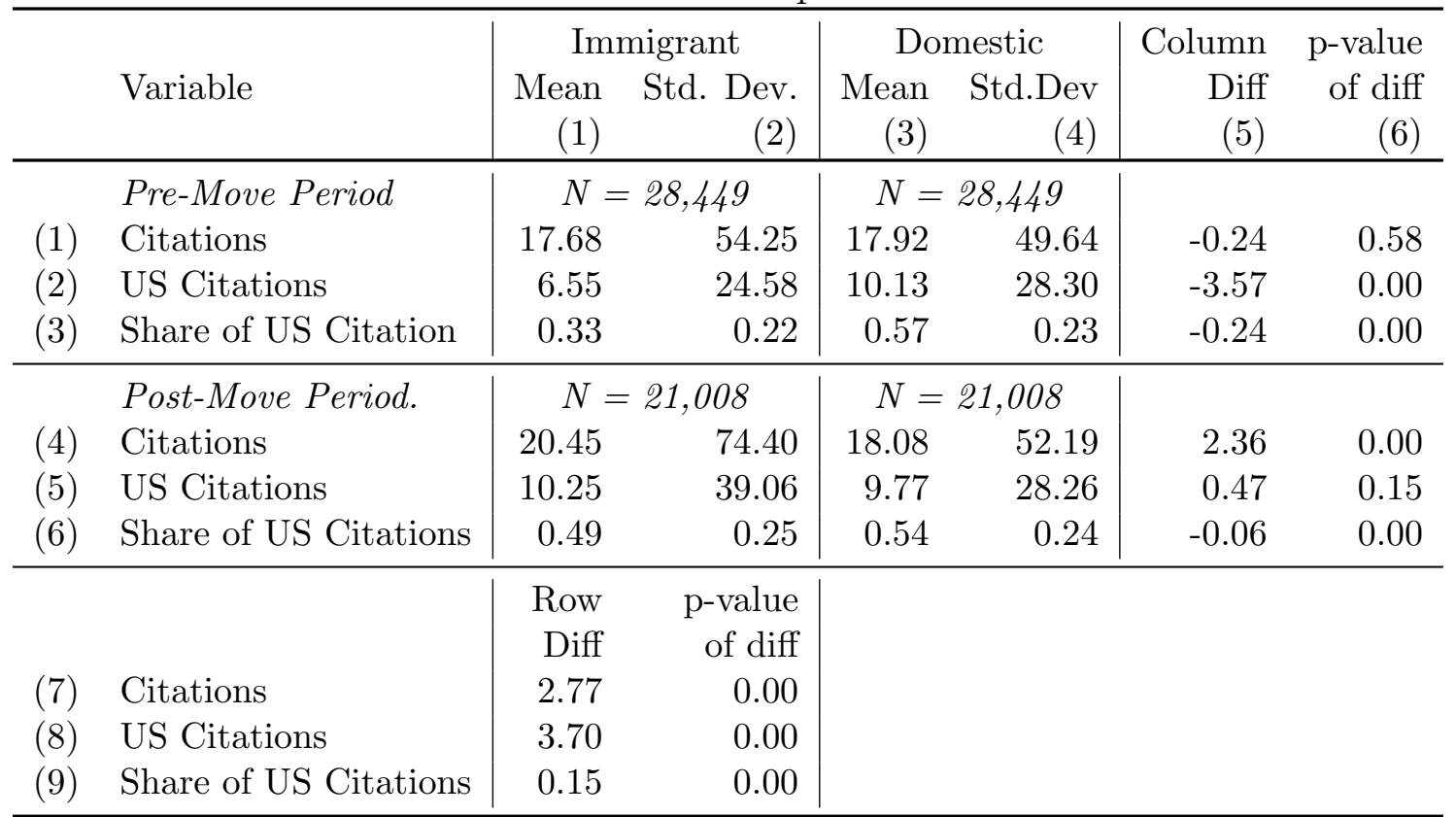

Notes: Each observation is at the scientist-year level. Citations is the mean sum of the number of forward citations to papers published by the scientist in the specific time period (pre or post move). US Citations is the mean annual count of the number of forward citations to papers published by scientist $i$ in the time period where the first author of the citing paper resides in the US. Immigrant and domestic scientists are matched using coarsened exact matching along the following dimensions: scientist age, total citations within the US, and discipline. 
Table 6: Mean Comparisons of Citations (Star Sample)

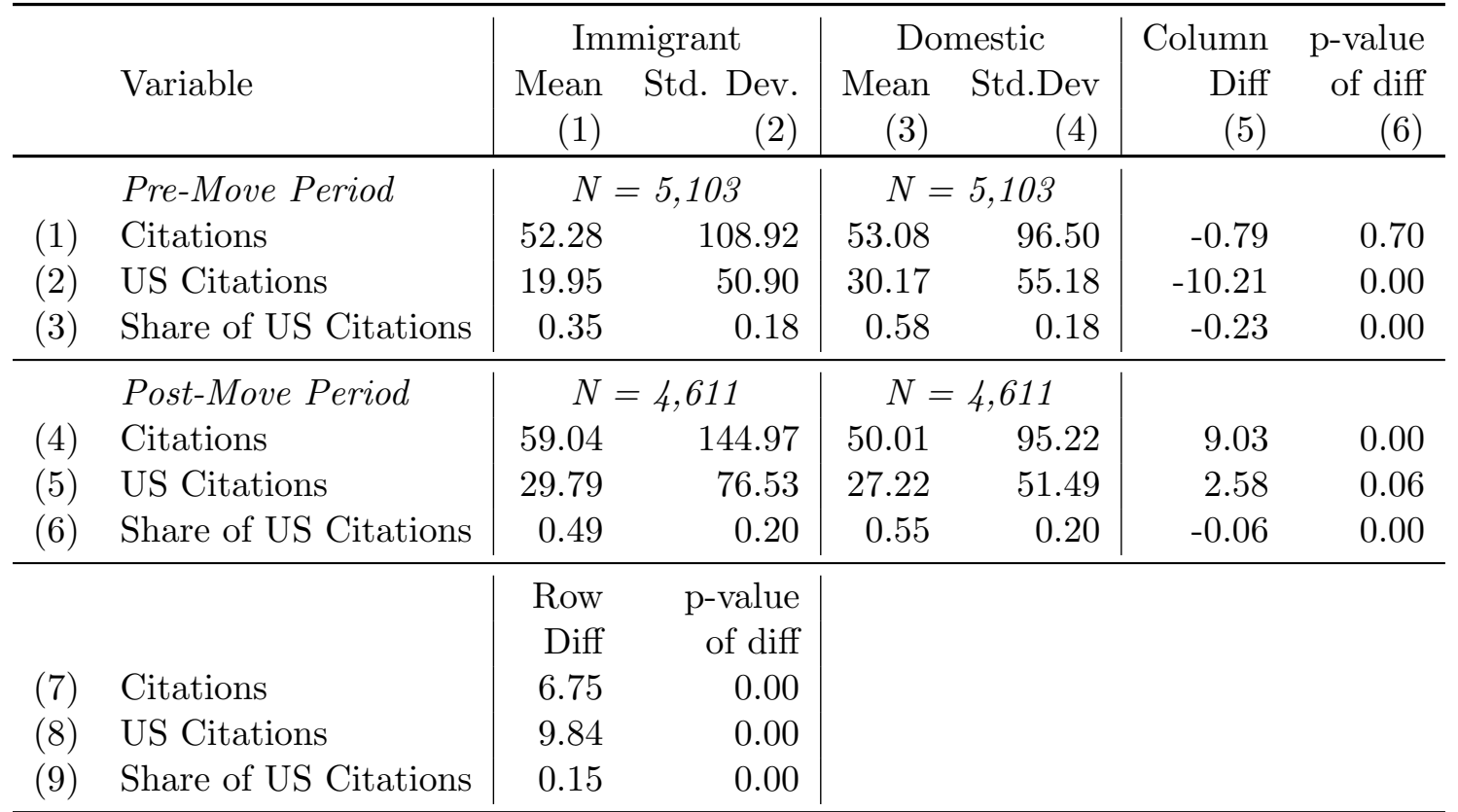

Notes: Each observation is at the scientist-year level. Citations is the mean sum of the number of forward citations to papers published by the scientist in the specific time period (pre or post move). US Citations is the mean annual count of the number of forward citations to papers published by scientist $i$ in the time period where the first author of the citing paper resides in the US. Immigrant and domestic scientists are matched using coarsened exact matching along the following dimensions: scientist age, total citations within the US, and discipline. 


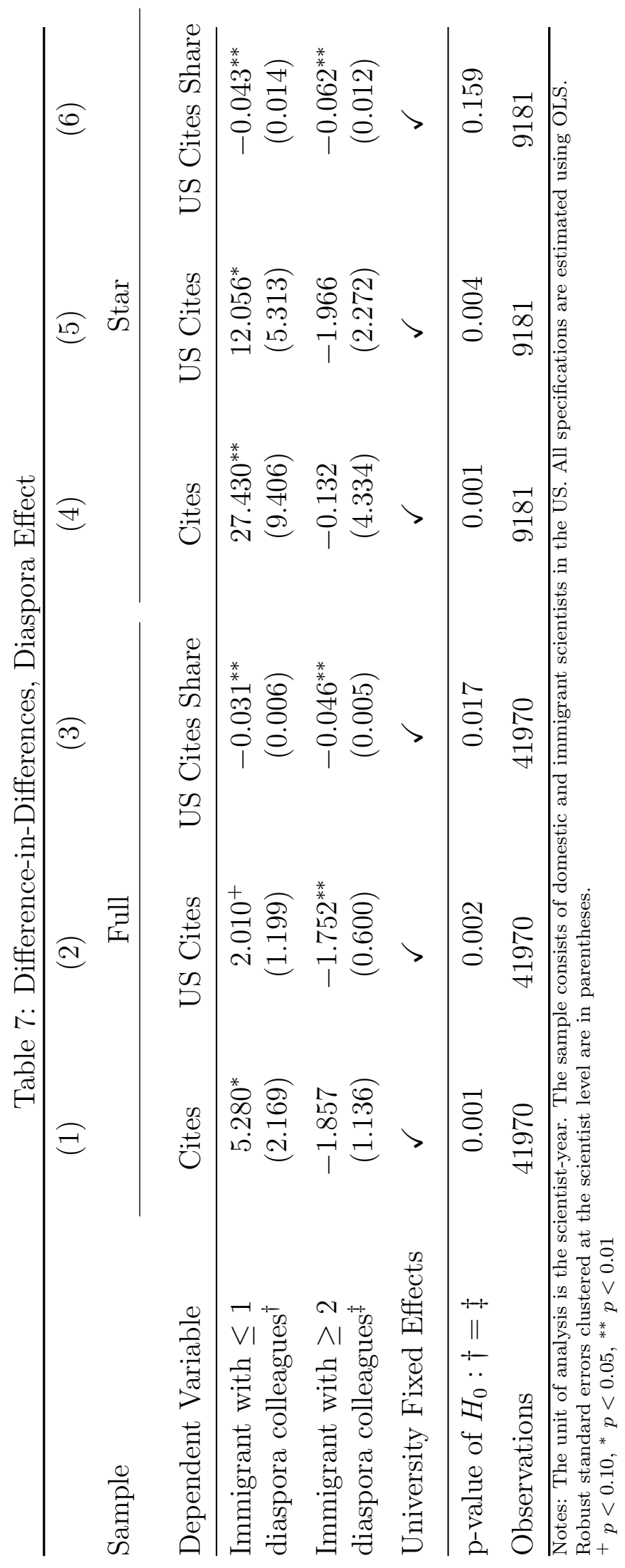




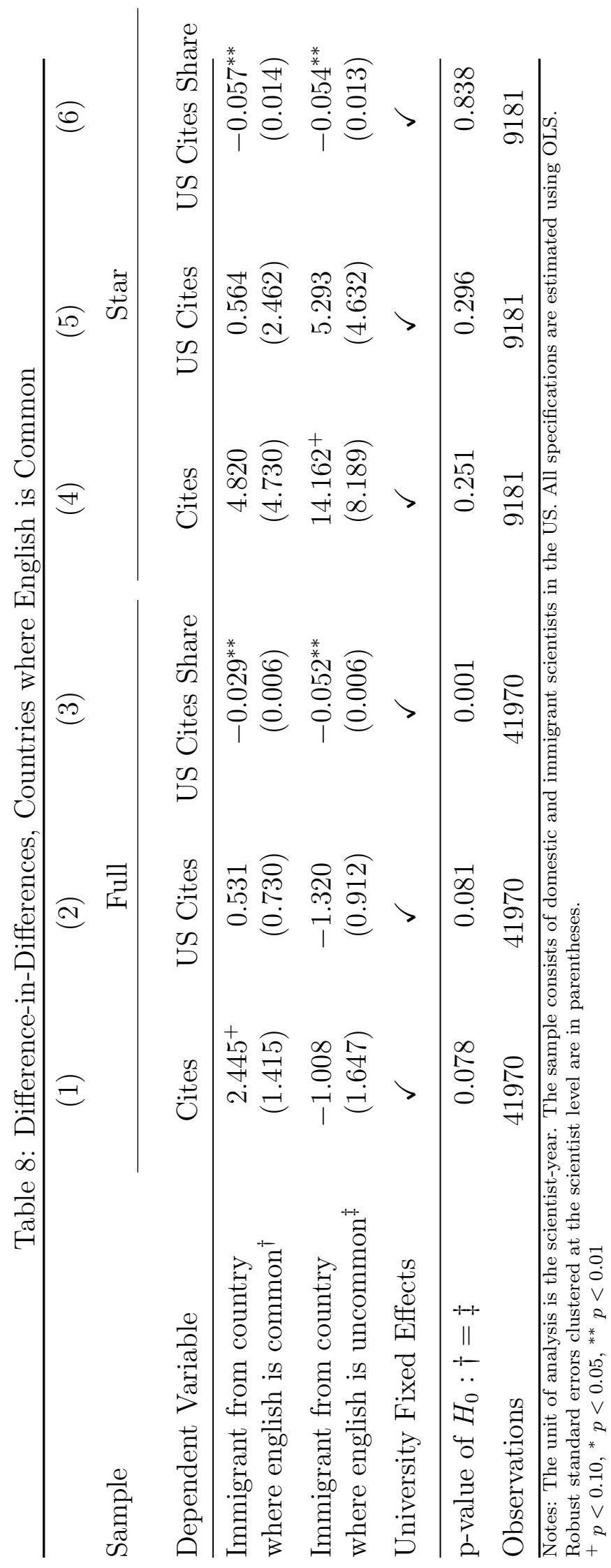

